\title{
sensors
}

ISSN 1424-8220

(C) 2007 by MDPI

www.mdpi.org/sensors

Full Research Paper

\section{Combination of On-line pH and Oxygen Transfer Rate Measurement in Shake Flasks by Fiber Optical Technique and Respiration Activity MOnitoring $\underline{\text { System }}$ (RAMOS)}

\section{Marco Scheidle, Johannes Klinger and Jochen Büchs *}

Biochemical Engineering, RWTH Aachen University, Sammelbau Biologie, Worringerweg 1, D52074 Aachen, Germany

E-mail: scheidle@biovt.rwth-aachen.de.E-mail: klinger@biovt.rwth-aachen.de

* Author to whom correspondence should be addressed. E-mail: buechs@biovt.rwth-aachen.de

Received: 3 December 2007 / Accepted: 20 December 2007 / Published: 20 December 2007

\begin{abstract}
Shake flasks are commonly used for process development in biotechnology industry. For this purpose a lot of information is required from the growth conditions during the fermentation experiments. Therefore, Anderlei et al. developed the RAMOS technology $[1,2]$, which proviedes on-line oxygen and carbondioxide transfer rates in shake flasks. Besides oxygen consumption, the $\mathrm{pH}$ in the medium also plays an important role for the successful cultivation of micro-organisms and for process development. For online $\mathrm{pH}$ measurement fiber optical methods based on fluorophores are available. Here a combination of the on-line Oxygen Transfer Rate (OTR) measurements in the RAMOS device with an on-line, fiber optical $\mathrm{pH}$ measurement is presented. To demonstrate the application of the combined measurement techniques, Escherichia coli cultivations were performed and online $\mathrm{pH}$ measurements were compared with off-line samples. The combination of on-line OTR and $\mathrm{pH}$ measurements gives a lot of information about the cultivation and, therefore, it is a powerful technique for monitoring shake flask experiments as well as for process development.
\end{abstract}

Keywords: fiber optical $\mathrm{pH}$ measurement, shaking flask, oxygen transfer rate, RAMOS, $E$. coli, process development 


\section{Introduction}

Up to now shaking bioreactors are the most commonly used reaction vessels in microbiology and biotechnology [3]. Several thousand shake flask experiments are carried out annually for strain development, screening processes and media optimization in large companies [4, 8]. For such applications, especially for media optimization, monitoring of cultivation parameters is essential. The information obtained from these experiments with on-line monitoring gives a better insight into limitations, inhibitions and the physiological state of the organisms during the cultivation, thus, allowing the development of optimized production processes in the biotechnology industry.

Anderlei et al. presented the Respiration Activity MOnitoring System (RAMOS) for on-line measurements of the respiration activity parameters (OTR, carbon dioxide transfer rate (CTR) and the respiratory quotient (RQ)) in shaking flasks $[1,2]$. Measuring OTR online during cultivation is the most suitable way to quantify the physiological state of aerobic micro-organisms. For example, oxygen limitations, product inhibition and diauxic growth could be identified. This device was successfully employed in different projects $[6,9,11,15-17,21,22,25]$. Losen et al. used the RAMOS for the optimization of culture conditions and nutrient composition of the medium for Escherichia coli fermentations in shake flasks [15]. The RAMOS technology is especially suitable for the optimization of screening cultures. Stoeckmann et al. demonstrated the impact of oxgen limitations during screening processes with Hansenula polymorpha [25, 26] and Zimmermann et al. for Corynebcterium glutamicum [28].

Other critical parameters during fermentation processes are $\mathrm{pH}$ values and $\mathrm{pH}$ changes. There are different factors that affect the $\mathrm{pH}$ during the growth of micro-organisms. For example, in aerobic culture with high glucose concentrations $E$. coli produces acetate due to overflow metabolism, which causes a decreasing $\mathrm{pH}$ of the medium. After the glucose is depleted E. coli may consume the acetate as a second carbon source in a diauxic manner so that the $\mathrm{pH}$ increases again. Furthermore, the $\mathrm{pH}$ value in $E$. coli fermentations in mineral medium with glucose or glycerol as sole carbon source is highly dependent on ammonium consumption. Uptake of one ammonium molecule generates one proton $[5,23]$ and, therefore, the $\mathrm{pH}$ value in the medium declines.

For the $\mathrm{pH}$ monitoring of dairy starter cultures in 96-well micro titer plates John et al. presented an optical method based on two different fluorophores [12]. One fluorophore is $\mathrm{pH}$ sensitive (indicator) and the other is $\mathrm{pH}$ insensitive (reference). To determine the actual $\mathrm{pH}$ in the solution the fluorescence intensities of both fluorophores are measured and with the ratio of both values the $\mathrm{pH}$ is calculated [12]. Another method for the fiber optical $\mathrm{pH}$ measurement in small scale fermentation processes is the dual lifetime referencing (DLR). This method was published by Huber et al. for optical measurement of seawater salinity [10]. DLR is based on the measurement fluorescence decay times of an indicator. The intensity of the excitation light is modulated at a specific frequency and the over-all phase shift of the light emitted by a pH-indicator and a reference fluorophore is evaluated. The company Presens (Precision Sensing GmbH, Regensburg, Germany) commercialized this technology in form of sensor spots, e.g. for the $\mathrm{pH}$ measurement in micro titer plates (Hydroplates). This technique was used by Puskeiler et al. for at-line pH-determination in micro titer plates [18]. Kensy et al. demonstrated the application of the technology for on-line monitoring of dissolved oxygen and $\mathrm{pH}$ in continuous shaken E. coli cultivations performed in 24-well micro titer plates [13]. 
In this work a fiber optical online $\mathrm{pH}$-measurement was combined with the OTR-measurement in the RAMOS device. The successful combined application of both measurement techniques were demonstrated in E. coli cultivations.

\section{Results and Discussion}

\subsection{On-line measurement of OTR and $\mathrm{pH}$ in the Respiration Activity MOnitoring System (RAMOS)}

E. coli BL 21 pLys pRset eYFP-IL6 was cultivated in the RAMOS device both with and without a sensor spot for $\mathrm{pH}$ on-line monitoring. Figure 1 shows the development of the OTR and the $\mathrm{pH}$ in the RAMOS-flask with sensor spot.

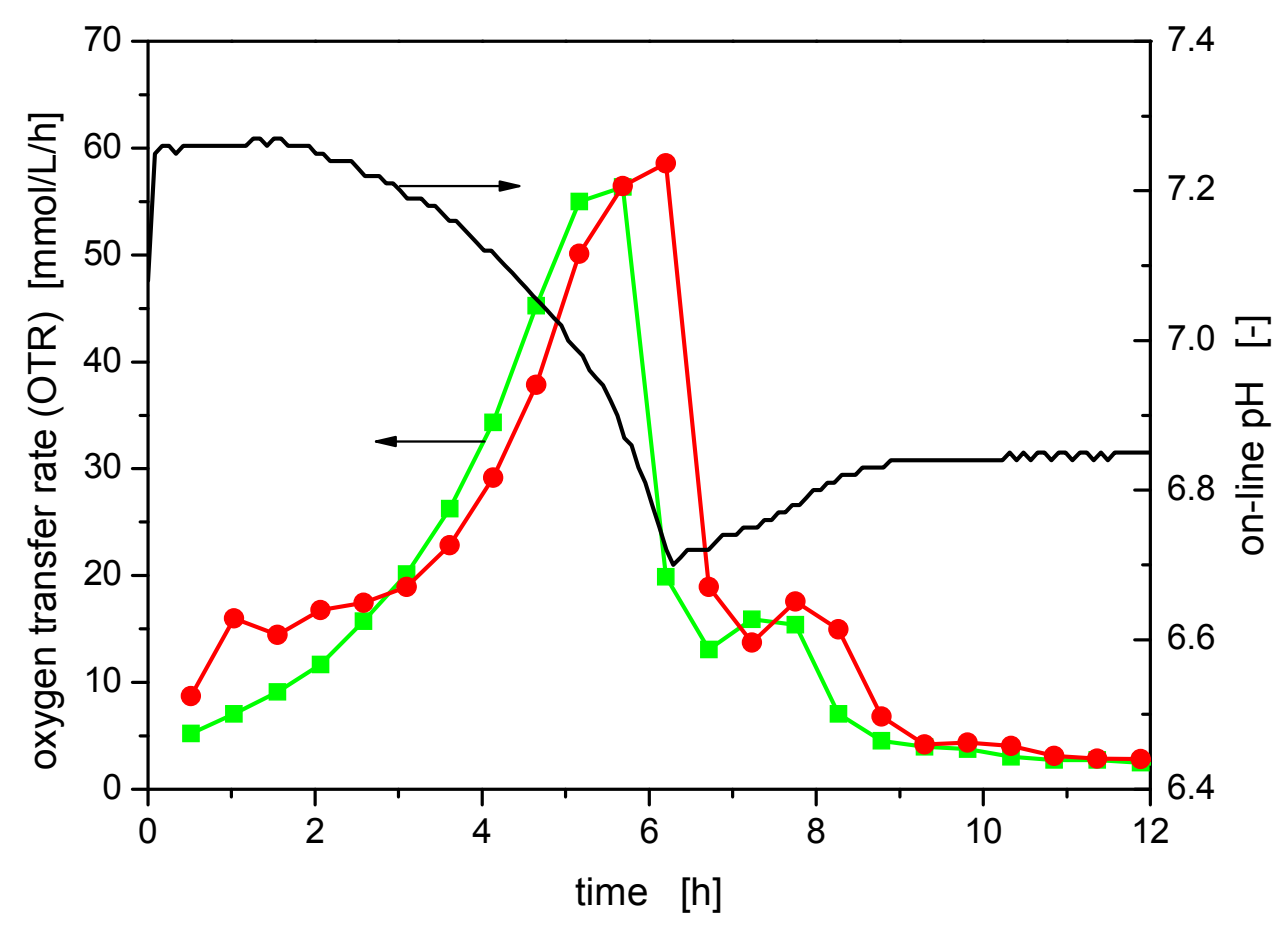

Figure 1: On-line measurement of OTR and $\mathrm{pH}$ in E. coli BL 21 pLys pRset eYFP-IL6 cultivations; modified Wilms \& Reuss medium; cultivation conditions: $\mathrm{T}=37^{\circ} \mathrm{C} ; \mathrm{d}_{0}=50 \mathrm{~mm} ; \mathrm{n}=350 \mathrm{rpm} ; \mathrm{V}_{\mathrm{L}}=$ $10 \mathrm{~mL} ; \mathrm{OD}_{\alpha}=0.5 ; \mathrm{pH}_{\alpha}=7.3$; legend: - OTR (flask without $\mathrm{pH}$ measurement); $\longrightarrow$ OTR (flask with on-line $\mathrm{pH}$ measurement);

The OTR of the cultivations with and without sensor spot proceeded more or less in parallel. In the flask with sensor spot the OTR curve is only slightly delayed. This might be due to slightly different inocula.

Without any lag-phase the bacteria started to grow so that the OTR increases directly. At the beginning of the cultivation the $\mathrm{pH}$ stays constant, because the acidification of the medium caused by the metabolic activity of the organisms is completely compensated by the buffer capacity. During the exponential growth of the micro-organisms after 2 hours fermentation time, the $\mathrm{pH}$ declines due to the increasing consumption of ammonium and the production of acetate in the overflow metabolism as 
discussed by Christensen et al. [5]. After $6 \mathrm{~h}$ the first carbon source glucose is exhausted and therefore the OTR declines rapidly. Thereafter, the OTR shows a second peak, while simultaneously the $\mathrm{pH}$ rises. From this point the organisms consume acetate as second carbon source. Due to the removal of acidic acetate, the $\mathrm{pH}$ of the medium increases until the acetate is depleted and the micro-organisms enter the stationary phase after $9 \mathrm{~h}$. In the stationary phase the $\mathrm{pH}$ stays constant and the OTR declines to a low level.

\subsection{Comparison of off-line and on-line $\mathrm{pH}$ measurement}

To compare on-line and off-line $\mathrm{pH}$ measurements E. coli BL 21 pLys pRset eYFP-IL6 was cultivated in the RAMOS device and in parallel in normal shake flasks for sampling. Figure 2 shows the courses of both measured $\mathrm{pH}$ values.

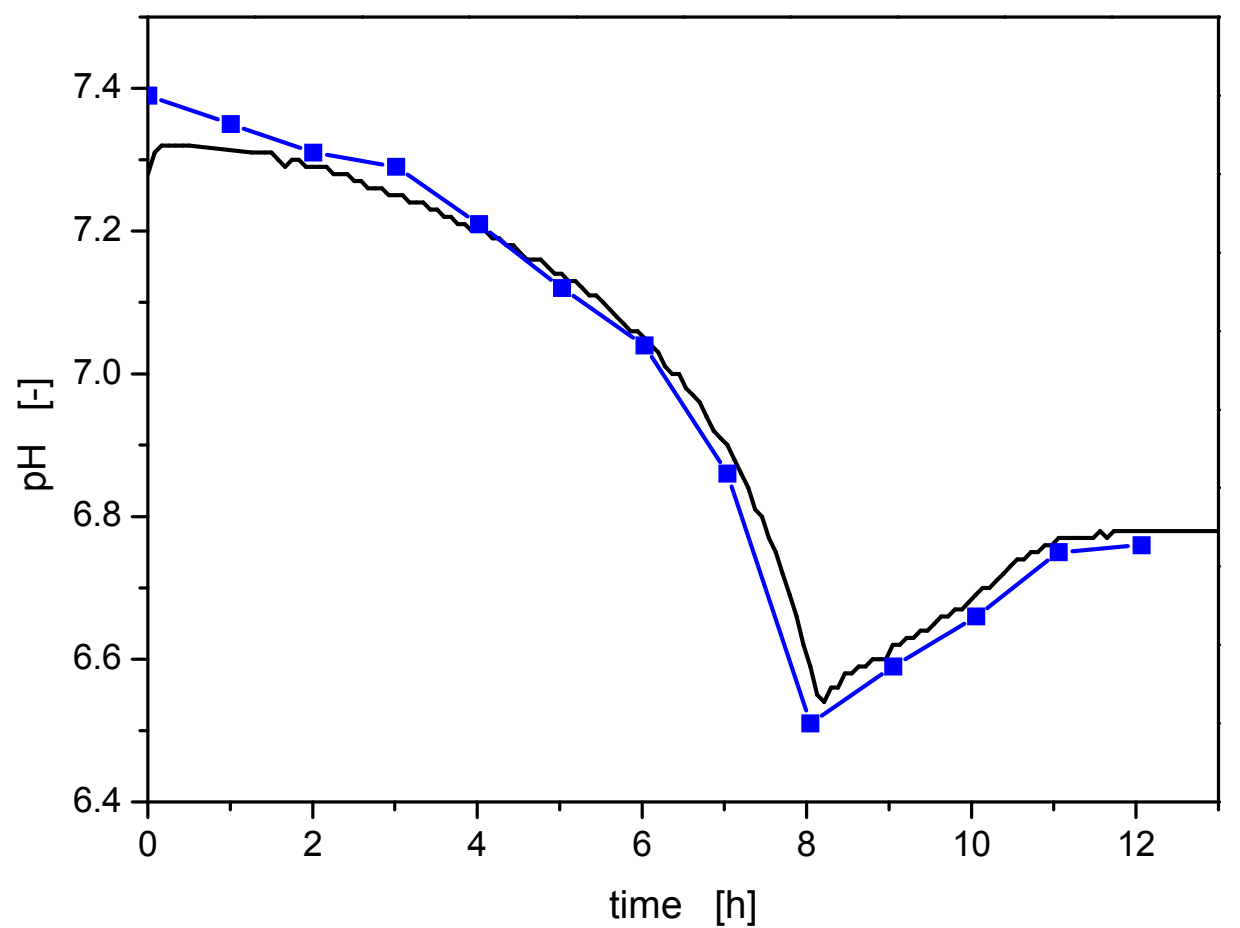

Figure 2: Comparison of off-line and on-line $\mathrm{pH}$ measurements in an E. coli BL $21 \mathrm{pLys}$ pRset eYFP-IL6 cultivation; modified Wilms \& Reuss medium ; cultivation conditions: $\mathrm{T}=37^{\circ} \mathrm{C} ; \mathrm{d}_{0}=50$ $\mathrm{mm} ; \mathrm{n}=350 \mathrm{rpm} ; \mathrm{V}_{\mathrm{L}}=10 \mathrm{~mL} ; \mathrm{OD}_{\alpha}=0.5 \mathrm{pH}_{\alpha}=7.3$; legend: $\longrightarrow$ on-line $\mathrm{pH} ; \boldsymbol{C}$ off-line $\mathrm{pH}$

The $\mathrm{pH}$ courses show typical shapes for cultivations of $E$. coli BL 21 pLys pRset eYFP-IL6 under the given conditions, which was already discussed in Figure 1. Both curves proceed in parallel and the maximum difference between on-line and off-line $\mathrm{pH}$ measurements was $\pm 0.05 \mathrm{pH}$. The highest difference occurs at the beginning of the cultivation.

The error in the different measurements averages to $\pm 0.02 \mathrm{pH}$, which lies in sum of the accuracies of the Eutech pH meter (Eutech Instruments Europe B.V., Nijkerk, Netherlands) and the pH-mini (Precision Sensing GmbH, Regensburg, Germany) with $0.01 \mathrm{pH}$, respectively (according to manufacturers). Therefore, the on-line $\mathrm{pH}$ measurement in the RAMOS device gives reliable results compared to the off-line measurement. 


\section{Conclusion}

The combination of the fiber optical, on-line $\mathrm{pH}$ and OTR measurements in the RAMOS device was successfully applied. This presented technique enables $\mathrm{pH}$ measurements in RAMOS flasks without sampling and stopping the shaking machine. Therefore, mass transfer and mixing are not interrupted during the cultivation. Seletztky et al. showed that interruptions could lead to anaerobic periods during cultivation and changes in the metabolic activity of the organisms [21]. Furthermore, the filling volume in the flasks does not change due to sampling, which allows an undisturbed growth of microorganisms. Moreover, a better comparability of the $\mathrm{pH}$ values during cultivations in RAMOS flasks and normal shake flasks is achieved.

The $\mathrm{pH}$ effects on the OTR during growth of micro-organisms, e.g. inhibited growth due to too low $\mathrm{pH}$ values, can easily be identified with this measuring setup. Furthermore, the on-line $\mathrm{pH}$ measurement gives a higher resolution than the off-line $\mathrm{pH}$ measurement. For instance, $\mathrm{pH}$ changes could be resolved more precisely in the on-line $\mathrm{pH}$ compared to the off-line measurement, providing better information about the process.

The here presented measurement technique is especially useful for media and cultivation optimization. Oxygen supply and buffer concentrations of media can be checked and adapted to the requirements of the microbial growth. Adaptation and regulation of growth conditions is of utmost importance for organisms with complex growth behavior, which produce and/or consume different $\mathrm{pH}$ affecting substances like acetate, lactate or glutamate. For instance, Gluconobacter oxydans produces 5-keto-D-gluconate, 2-ketogluconate and 2,5-diketogluconate on glucose as sole carbon source, whereas the product formation is highly dependent on the $\mathrm{pH}$-value and the oxygen supply during the fermentation $[7,14,19,24]$. Thereby the $\mathrm{pH}$ profile of the $G$. oxydans cultivation must be adjusted to the desired product [15] and the acidification caused by the products must be considered.

The combination of the on-line OTR and $\mathrm{pH}$ measurement gives a lot of information about the cultivation and, therefore, is a powerful technique for the monitoring of shake flask experiments as well as for process development.

\section{Experimental Section}

\section{Organism and Cultivation Conditions}

E. coli BL 21 pLys pRset eYFP-IL6 [20] was maintained at $-80^{\circ} \mathrm{C}$ in $\mathrm{LB}$ medium with $100 \mu \mathrm{g} / \mathrm{mL}$ ampicilin. Stock solutions contained $200 \mathrm{~g} / \mathrm{L}$ glycerol (Carl Roth GmbH \& Co. KG, Karlsruhe, Germany).

All cultivations were performed at $37^{\circ} \mathrm{C}$ in $250 \mathrm{~mL}$ normal shaking flasks or RAMOS flasks, respectively, with $10 \mathrm{~mL}$ filling volume $\left(\mathrm{V}_{\mathrm{L}}\right)$. Shaking machines (LS-W in case of RAMOS device; ISF-4-W in case of normal shaking flasks) with a shaking diameter $\left(\mathrm{d}_{0}\right)$ of $50 \mathrm{~mm}$ from Adolf Kühner AG, Birsfelden, Switzerland were used. The shaking frequency (n) was $350 \mathrm{rpm}$. 


\section{Media and Solutions}

A modified Wilms \& Reuss [27] medium was used for the cultivations. The basic solution consists of $20 \mathrm{~g} / \mathrm{L}$ glucose; $5 \mathrm{~g} / \mathrm{L}\left(\mathrm{NH}_{4}\right)_{2} \mathrm{SO}_{4} ; 0.5 \mathrm{~g} / \mathrm{L} \quad \mathrm{NH}_{4} \mathrm{Cl} ; 3 \mathrm{~g} / \mathrm{L} \quad \mathrm{K}_{2} \mathrm{HPO}_{4} ; 2 \mathrm{~g} / \mathrm{L} \quad \mathrm{Na}_{2} \mathrm{SO}_{4} ; 0.5 \mathrm{~g} / \mathrm{L}$ $\mathrm{MgSO}_{4} \cdot 7 \mathrm{H}_{2} \mathrm{O} ; 41,85 \mathrm{~g} / \mathrm{L}$ 3-(N-Morpholino)-propanesulfonic acid (MOPS); $0.1 \mathrm{~g} / \mathrm{L}$ ampicillin; 0.01 $\mathrm{g} / \mathrm{L}$ thiamine hydrochloride; $1 \mathrm{~mL} / \mathrm{L}$ trace element solution $\left[0.54 \mathrm{~g} / \mathrm{L} \mathrm{ZnSO}_{4} \cdot 7 \mathrm{H}_{2} \mathrm{O} ; 0.48 \mathrm{~g} / \mathrm{L}\right.$ $\mathrm{CuSO}_{4} \cdot 5 \mathrm{H}_{2} \mathrm{O} ; 0.3 \mathrm{~g} / \mathrm{L} \quad \mathrm{MnSO}_{4} \bullet \mathrm{H}_{2} \mathrm{O} ; 0.54 \mathrm{~g} / \mathrm{L} \quad \mathrm{CoCl}_{2} \bullet 6 \mathrm{H}_{2} \mathrm{O} ; 41.76 \mathrm{~g} / \mathrm{L} \quad \mathrm{FeCl}_{3} \bullet 6 \mathrm{H}_{2} \mathrm{O} ; 1.98 \mathrm{~g} / \mathrm{L}$ $\mathrm{CaCl}_{2} \cdot 2 \mathrm{H}_{2} \mathrm{O} ; 33.39 \mathrm{~g} / \mathrm{L} \mathrm{Na} \mathrm{NaDTA}_{2}$ (Titriplex III)]. The $\mathrm{pH}$ was adjusted to 7.3 with $\mathrm{NaOH}$. All reagents were of analytical grade and purchased from Carl Roth $\mathrm{GmbH} \&$ Co. KG, Karlsruhe, Germany.

\section{Online-Measurement of Oxygen Transfer Rates with the RAMOS Device}

The RAMOS device for the on-line measurement of the OTR in shake flasks was introduced by Anderlei et al. [1, 2]. The cultivations in the RAMOS device were performed in modified $250 \mathrm{~mL}$ Erlenmeyer flasks. In the RAMOS flasks the hydrodynamic conditions and the concentrations in the gas-phase of the head space are the same as in regular Erlenmeyer flasks with cotton plugs [2].

\section{Samples and off-line pH-Measurement}

Büchs 2001 [3] described the problem of oxygen limitation while taking samples from the RAMOS flasks during the cultivation. Therefore, additional Erlenmeyer flasks were used for sampling. The cultivations in these flasks were performed in parallel and under the same conditions as the cultivations in the RAMOS device. For each sample the shaking machine was stopped and two flasks were taken from the machine. After taking a $1 \mathrm{~mL}$ sample the filling volume was refilled with sterile, purified water. Each flask was used for two samples.

The off-line $\mathrm{pH}$ was measured with a CyberScan $\mathrm{pH} 510$ (Eutech, Nijkerk, The Netherlands) pH meter at $37^{\circ} \mathrm{C}$.

\section{On-line pH Measurement by Fiber Optical Technique}

Commercially available sterile $\mathrm{pH}$ sensitive sensor spots (Presens, Regensburg, Germany) were applied for the fiber optical on-line $\mathrm{pH}$ measurement in the RAMOS flask. For gluing senor spots into the RAMOS flasks silicone rubber compound (RS, Mörfelden-Walldorf, Germany) was used. The spot was glued with a wet stick under the clean bench at the inside glass wall of autoclaved flasks at the point with the highest flask diameter (Fig. 3). A pH-1 mini (Presens, Regensburg, Germany) with an optical fiber to illuminate and collect the emitted fluorescence from the sensor spot, was used as $\mathrm{pH}$ meter.

The calibration was performed unsterile prior to a cultivation experiment with one sensor spot. For calibration six different buffers adjusted to different $\mathrm{pH}$ values between $\mathrm{pH} 4$ and 9 were used to cover the measuring range. It was proven that the calibration was stable for the following on-line measurements with further sterile sensor spots from the same batch (data not shown). After 5 experiments a new calibration was performed. 
For the analysis of the optical $\mathrm{pH}$ measurement a Visual Basic application in Mircosoft Excel was kindly provided by Frank Kensy (m2p-laps, Aachen, Germany).

\section{Combination of On-line $p H$ Measurement and the RAMOS device}

To fix the optical fiber on the RAMOS plate, a holder was mounted next to one of the RAMOS flasks (Fig. 3), so that the fluorescence intensities of the fluorophores in the sensor spot could be measured.

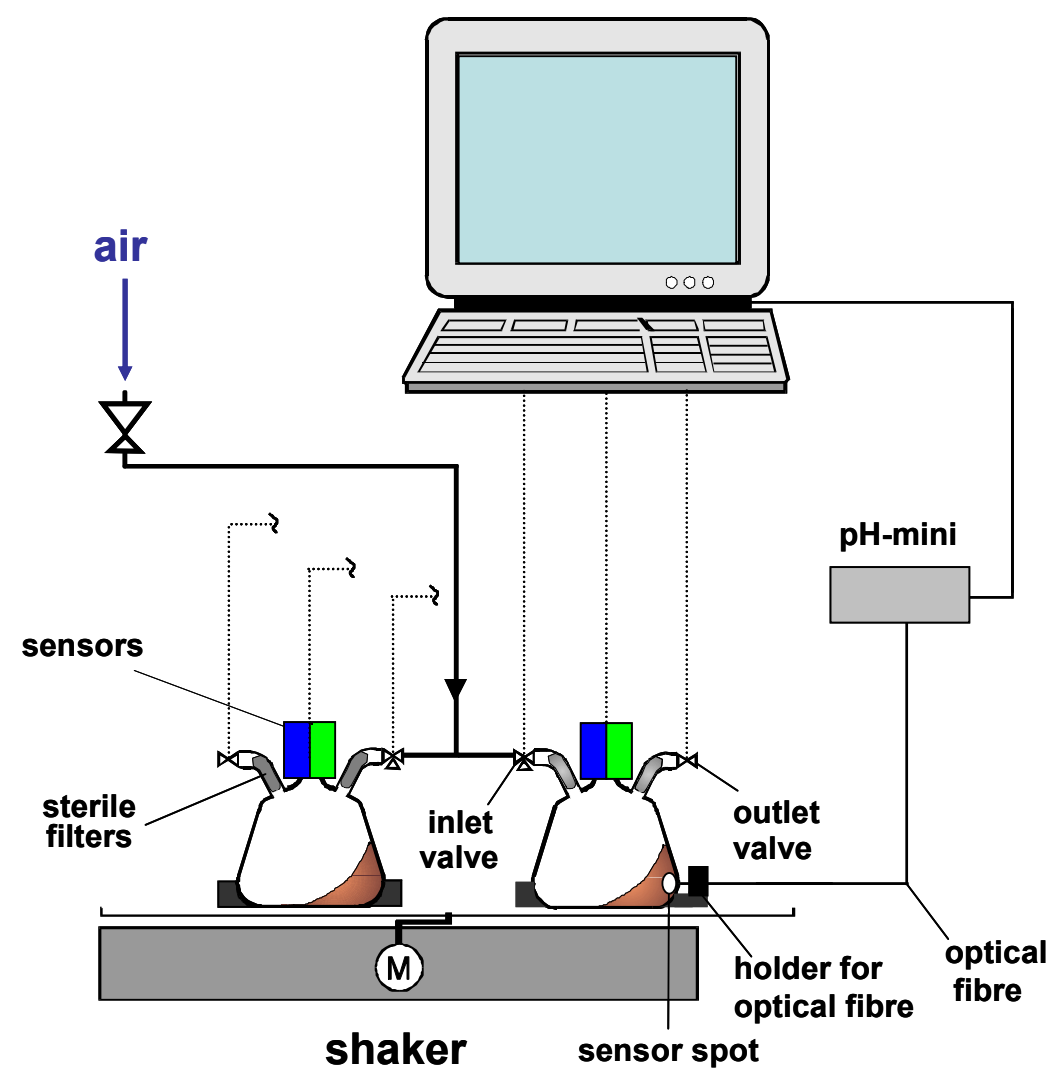

Figure 3: Principal set-up of RAMOS in combination with fiber optical, on-line $\mathrm{pH}$ measurement.

\section{Nomenclature}

CTR carbon dioxid transfer rate $[\mathrm{mol} / \mathrm{Lh}]$

$\mathrm{d}_{0} \quad$ orbital shaking diameter $[\mathrm{mm}]$

$\mathrm{n} \quad$ shaking frequency $[\mathrm{rpm}]$

OTR oxygen transfer rate [mol/Lh]

RAMOS Respiration Activity Monitoring System

RQ respiratory quotient [-]

$\mathrm{T}$ temprature $\left[{ }^{\circ} \mathrm{C}\right]$

$\mathrm{V}_{\mathrm{L}} \quad$ filling volume $[\mathrm{mL}]$ 


\section{Acknowledgements}

We thank the Deutsche Bundesstiftung Umwelt for funding part of this work.

\section{References and Notes}

1. Anderlei, T.; Büchs, J. Device for sterile online measurement of the oxygen transfer rate in shaking flasks. Biochemical Engineering Journal 2001, 7(2), 157-162.

2. Anderlei, T.; Zang, W.; Papaspyrou, M.; Büchs, J. Online respiration activity measurement (OTR, CTR, RQ) in shake flasks. Biochemical Engineering Journal 2004, 17(3), 187-194.

3. Büchs, J. Introduction to advantages and problems of shaken cultures. Biochemical Engineering Journal 2001, 7(2), 91-98.

4. Büchs, J. Biochemical Engineering Journal - Preface. Biochemical Engineering Journal 2004, 17(3), 153-153.

5. Christensen, M.L.; Eriksen, N.T. Growth and proton exchange in recombinant Escherichia coli BL21. Enzyme and Microbial Technology 2002, 31, 566-574.

6. Danielson, P.B.; Büchs, J.; Stockmann, C.; Fogleman, J.C. Maximizing cell densities in miniprepscale cultures with H15 medium and improved oxygen transfer. Biochemical Engineering Journal 2004, 17(3), 175-180.

7. De Ley, J.; Gillis, M.; Swings, J. The genus Gluconobacter. In Bergey's manual of systematic bacteriology, $1^{\text {st }}$ Ed.; Krieg N.R., Holt J.G., Eds.; Williams and Wilkins: Baltimore, 1984; 1, $267-$ 278.

8. Freyer, S.A.; König, M.; Künkel, A. Validating shaking flasks as representativ screening systems. Biochemical Engineering Journal 2004, 17, 169-173.

9. Hermann, R.; Walther, N.; Maier, U.; Büchs, J. Optical method for the determination of the oxygen-transfer capacity of small bioreactors based on sulfite oxidation. Biotechnology and Bioengineering 2001, 74(5), 355-363.

10. Huber, C.; Klimant, I.; Krause, C.; Werner, T.; Mayr, T.; Wolfbeis, O.S. Optical sensor for seawater salinity. Fresenius' Journal of Analytical Chemistry 2000, 368(2), 196-202.

11. Jeude, M.; Dittrich, B.; Niederschulte, H.; Anderlei, T.; Knocke, C.; Klee, D.; Büchs, J. Fedbatch mode in shake flasks by slow-release technique. Biotechnol Bioeng 2006, 95(3), 433-45.

12. John, G.T.; Goelling, D.; Klimant, I.; Schneider, H.; Heinzle, E. pH-sensing 96-well microtitre plates for the characterization of acid production by dairy starter cultures. J Dairy Res $\mathbf{2 0 0 3 ,}$ $70(3), 327-33$.

13. Kensy, F.; John, G.T.; Hofmann, B.; Buchs, J. Characterisation of operation conditions and online monitoring of physiological culture parameters in shaken 24-well microtiter plates. Bioprocess and Biosystems Engineering 2005, 28(2), 75-81.

14. Levering, P.R.; Weenk, G.; Olijve, W.; Dijkhuizen, L.; Harder, W. Regulation of gluconate and ketogluconate production in Gluconobacter oxydans ATCC 621-H. Archives of Microbiology 1988, 149(6), 534-539.

15. Losen, M.; Frolich, B.; Pohl, M.; Büchs, J. Effect of oxygen limitation and medium composition on Escherichia coli fermentation in shake-flask cultures. Biotechnology Progress 2004, 20(4), 1062-1068. 
16. Maier, U.; Losen, M.; Büchs, J. Advances in understanding and modeling the gas-liquid mass transfer in shake flasks. Biochemical Engineering Journal 2004, 17(3), 155-167.

17. Peter, C.P.; Lotter, S.; Maier, U.; Büchs, J. Impact of out-of-phase conditions on screening results in shaking flask experiments. Biochemical Engineering Journal 2004, 17(3), 205-215.

18. Puskeiler, R.; Kusterer, A.; John, G.T.; Weuster-Botz, D. Miniature bioreactors for automated high-throughput bioprocess design (HTBD): Reproducibility of parallel fed-batch cultivations with Escherichia coli. Biotechnol Appl Biochem 2005.

19. Qazi, G.N.; Parshad, R.; Verma, V.; Chopra, C.L.; Buse, R.; Trager, M.; Onken, U. Diketogluconate fermentation by Gluconobacter oxydans. Enzyme and Microbial Technology 1991, 13(6), 504-507.

20. Samorski, M.; Müller-Newen, G.; Büchs, J. Quasi-continuous combined scattered light and fluorescence measurements: a novel measurement technique for shaken microtiter plates. Biotechnol Bioeng 2005, 92(1), 61-8.

21. Seletzky, J.; Noack, U.; Fricke, J.; Hahn, S.; Büchs, J. Metabolic activity of Corynebacterium glutamicum grown on 1 -lactic acid under stress. Applied Microbiology and Biotechnology 2006, 72(6), 1297-1307.

22. Seletzky, J.M.; Noack, U.; Hahn, S.; Knoll, A.; Amoabediny, G.; Büchs, J. An experimental comparison of respiration measuring techniques in fermenters and shake flasks: exhaust gas analyzer vs. RAMOS device vs. respirometer. J Ind Microbiol Biotechnol 2007, 34(2), 123-30.

23. Siano, S.A. On the use of the $\mathrm{pH}$ control reagent addition rate for fermentation monitoring. Biotechnology and Bioengineering 1995, 47(6), 651-665.

24. Silberbach, M.; Maier, B.; Zimmermann, M.; Buchs, J. Glucose oxidation by Gluconobacter oxydans: characterization in shaking-flasks, scale-up and optimization of the $\mathrm{pH}$ profile. Applied Microbiology and Biotechnology 2003, 62(1), 92-98.

25. Stöckmann, C.; Losen, M.; Dahlems, U.; Knocke, C.; Gellissen, G.; Büchs, J. Effect of oxygen supply on passaging, stabilising and screening of recombinant Hansenula polymorpha production strains in test tube cultures. FEMS Yeast Res 2003, 4(2), 195-205.

26. Stöckmann, C.; Maier, U.; Anderlei, T.; Knocke, C.; Gellissen, G.; Büchs, J. The oxygen transfer rate as key parameter for the characterization of Hansenula polymorpha screening cultures. Journal of Industrial Microbiology \& Biotechnology 2003, 30(10), 613-622.

27. Wilms, B.; Hauck, A.; Reuss, M.; Syldatk, C.; Mattes, R.; Siemann, M.; Altenbuchner, J. Highcell-density fermentation for production of L-N-carbamoylase using an expression system based on the Escherichia coli rhaBAD promoter. Biotechnology and Bioengineering 2001, 73(2), 95103.

28. Zimmermann, H.F.; Anderlei, T.; Buchs, J.; Binder, M. Oxygen limitation is a pitfall during screening for industrial strains. Appl Microbiol Biotechnol 2006, 72(6), 1157-60.

(C) 2007 by MDPI (http://www.mdpi.org). Reproduction is permitted for noncommercial purposes. 